\title{
The Effect of Silicon on the Brittle Fracture of
}

Ferritic-Pearlitic Steels*

\section{By Yasuya OHMORI,** Yoshiaki KAWAGUCHI** and Yoji YAMAGUCHI***}

\begin{abstract}
Synopsis
The effect of silicon on the brittle fracture characteristics of ferriticpearlitic steels has been investigated by means of both Charpy impact and double cantilever beam tests.

Although the increase of silicon content largely raised the Charpy impact transition temperature at the same pearlite colony size, the brittle fracture propagation-arrest properties determined by the DCB test was not affected by silicon content. Since the Charpy transition temperature was closely related to that for cleavage fracture initiation obtained by the fatiguenotched COD test, the brittle fracture initiation properties are expected to be deteriorated by increasing silicon content. Such brittle fracture characteristics were in quite good agreement with the temperature dependence of lower yield stress.
\end{abstract}

\section{Introduction}

The increase of silicon content deteriorates the impact properties of steels with raising the room temperature strength., ${ }^{1,2)}$ In the commercial low alloy steels, however, the amount of silicon is normally below $0.6 \mathrm{wt} \%$, and it is commonly used as a beneficial alloying element for strengthening, because the loss of toughness is in an allowable range.

There are, however, not so many investigations which separated the pure solid solution hardening by silicon except that by Lacy and Gensamer ${ }^{3)}$ where the steels used were in a limited range of ferrite grain size and that by Takeuchi $^{4)}$ using Fe-Si single crystals. It should also be pointed out that, although $3 \% \mathrm{Si}$ addition increases the room temperature strength of iron, it exhibits the solid solution softening at lower temperatures. The relationship between this softening and the fracture behaviour has not been clearly understood.

The aim of the present investigation is to obtain the information about such effects of silicon in ferriticpearlitic steels, and the relationship between the microstructure, the impact properties and the brittle fracture propagation-arrest properties has been examined.

\section{Experimental Procedures}

\section{The Materials}

The chemical compositions of the steels used are shown in Table 1. They were melt in a $200 \mathrm{~kg}$ high frequency induction furnace, and the ingots were forged and rolled to $13 \mathrm{~mm}$-thick plates. The basic composition was $\mathrm{Fe}-1.45 \% \mathrm{Mn}-0.15 \% \mathrm{C}-0.05 \% \mathrm{Al}$ and the amount of silicon was varied from $0.05 \%$ (steel A) to $1.05 \%$ (steel D). The ferrite grain and the pearlite colony sizes were varied by the heat treatments described in Table 2.

\section{Microstructure and Mechanical Properties}

The microstructure was revealed in $2 \%$ nital and examined by an optical microscope. Both ferrite grain size and pearlite colony size were determined by lineal analysis method as the mean linear intercepts.

The mechanical properties were examined by the tensile tests in the temperature range between $-196^{\circ} \mathrm{C}$ and the room temperature, $2 \mathrm{~mm} \mathrm{~V}$-notch Charpy impact tests, and the DCB (Double Cantilever Beam) tests $^{6)}$ to obtain the brittle fracture propagation-arrest properties. The dimensions of a low temperature tensile specimen are shown in Fig. 1, and the test was conducted at the cross head velocity of $3 \mathrm{~mm} / \mathrm{min}$. Figure 2 shows the DCB specimen. The specimen was hold at a test temperature and the load was

Table 2. Heat treatments.

\begin{tabular}{c|cc|c}
\hline & \multicolumn{2}{|c|}{ Austenitization } & \\
\cline { 2 - 3 } & $\begin{array}{c}\text { Temperature } \\
\left({ }^{\circ} \mathrm{C}\right)\end{array}$ & $\begin{array}{c}\text { Time } \\
(\mathrm{min})\end{array}$ & \\
\hline 1 & 1300 & 120 & Cooling \\
\hline 2 & 1200 & 30 & furnace cooling \\
3 & 900 & 60 & furnace cooling \\
4 & 900 & 60 & air cooling \\
\hline
\end{tabular}

Table 1. Chemical compositions of the steels used. (wt \%)

\begin{tabular}{|c|c|c|c|c|c|c|c|c|c|}
\hline Steel & $\mathrm{C}$ & $\mathrm{Si}$ & $\mathrm{Mn}$ & $\mathrm{P}$ & $\mathrm{S}$ & $\mathrm{Cu}$ & $\mathrm{O}$ & $\mathrm{N}$ & $\mathrm{Al}$ \\
\hline A & 0.14 & 0.05 & 1.42 & 0.008 & 0.008 & 0.011 & 0.003 & 0.0068 & 0.061 \\
\hline B & 0.16 & 0.35 & 1.43 & 0.010 & 0.009 & 0.011 & 0.005 & 0.0084 & 0.042 \\
\hline C & 0.15 & 0.81 & 1.46 & 0.008 & 0.008 & 0.013 & 0.004 & 0.0068 & 0.054 \\
\hline $\mathrm{D}$ & 0.14 & 1.05 & 1.46 & 0.009 & 0.009 & 0.012 & 0.004 & 0.0067 & 0.056 \\
\hline
\end{tabular}

* Originally published in Tetsu-to-Hagané, 65 (1979), 1607, in Japanese. Formerly presented at the 96th ISIJ Meeting, October 1978, at Toyama University, Toyama 930. English version received August 8, 1979.

** Central Research Laboratories, Sumitomo Metal Industries, Ltd., Nishinagasu-hondori, Amagasaki 660.

*** Central Research Laboratories, Sumitomo Metal Industries, Ltd. Now at Wakayama Steel Works, Sumitomo Metal Industries, Ltd., Minato, Wakayama 640. 
applied through the pinholes. The cleavage fracture initiated at the brittle weld metal propagates along the side-grooves. Since the stress intensity factor $K$ decreases with the extension of crack, the propagation is arrested at the point where the $K$-value becomes lower than the $K_{c}$-value which is the critical stress intensity factor of the materials. ${ }^{6)}$ Thus the $K_{c}$-value for the arrest of brittle fracture propagation, $K_{c a}$, was determined at various temperatures.

\section{Experimental Results}

\section{Microstructure}

Photograph 1 illustrates the variation of ferriticpearlitic structure of $0.05 \% \mathrm{Si}$ steel by the heat treatments. The increase of silicon content did not produce the significant microstructural change, and it can be seen that the microstructure became finer with either lowering the austenitizing temperature or increasing the cooling rate from the austenitizing temperature. In order to assess the microstructural change quantitatively, the mean linear intercepts of ferrite grains and pearlite colonies were determined. The results are shown in Figs. 3 and 4 . It can be seen that both linear intercepts were largely affected

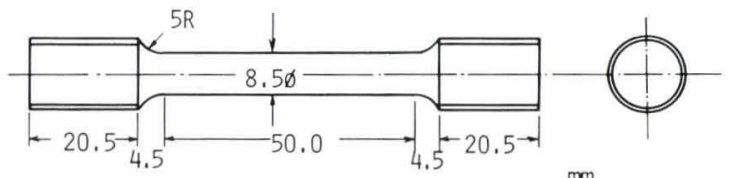

Fig. 1. Dimensions of tensile specimen

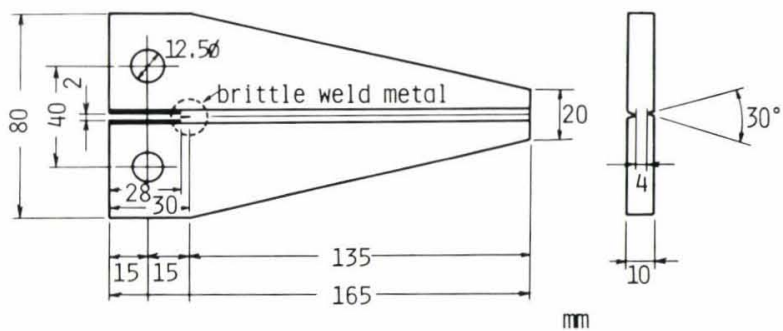

Fig. 2. Dimensions of Double Cantilever Beam test specimen. by the heat treatments, but that they hardly changed with the amount of silicon. It should be noted that the effect of cooling rate on pearlite colony size was much larger than that for ferrite grain size, i.e., in the case of $900^{\circ} \mathrm{C}$ austenitizing, the ferrite grain size of the steel cooled in the furnace was about 1.3 times larger than that cooled in air, but it was about 2 times for pearlite colony size.

\section{Mechanical Properties}

The relationships between the lower yield point and the ferrite grain size in the $0.05 \% \mathrm{Si}$ and the

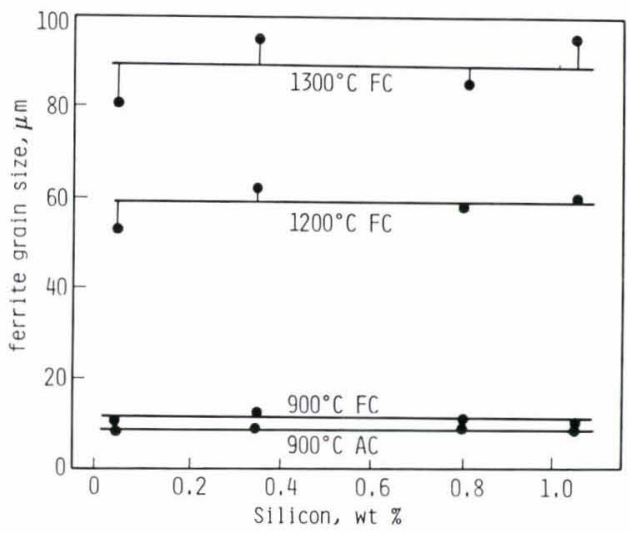

Fig. 3. Effect of the amount of $\mathrm{Si}$ on the ferrite grain size (linear intercept).

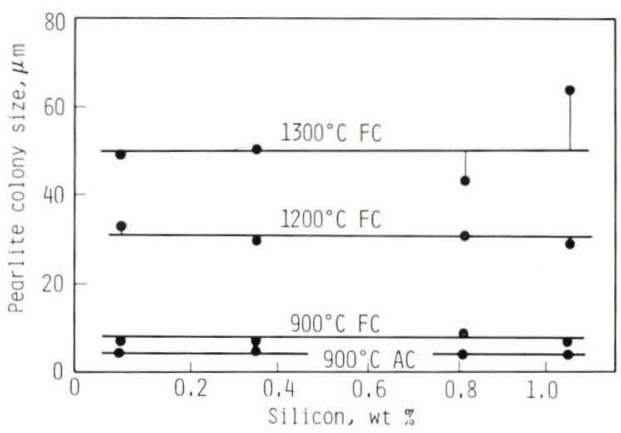

Fig. 4. Effect of the amount of $\mathrm{Si}$ on the pearlite colony size (linear intercept).

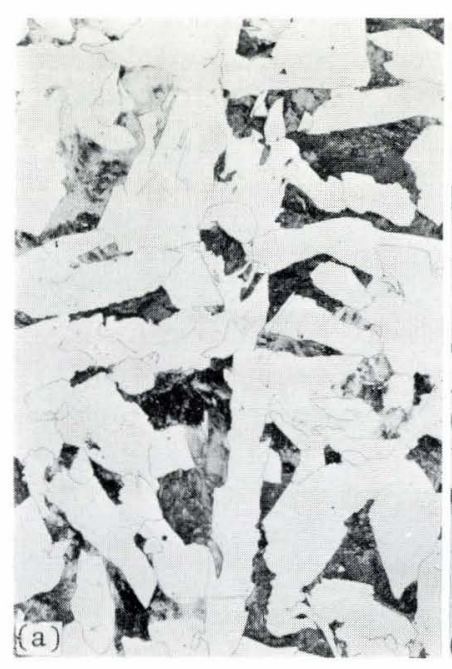

(a) $1300^{\circ} \mathrm{C} \times 120 \mathrm{~min}$ F. C.

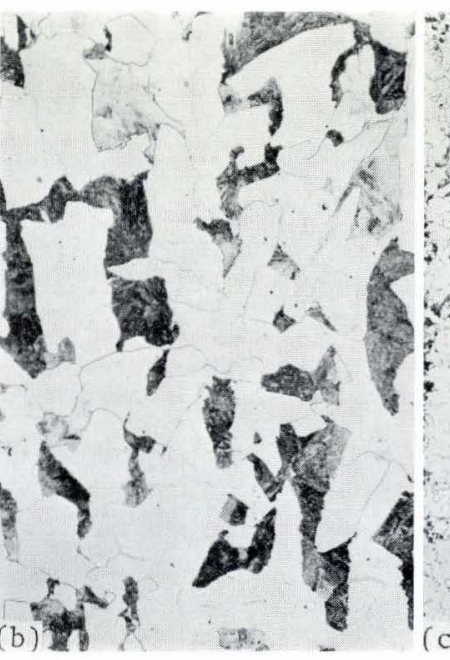

(b) $1200^{\circ} \mathrm{C} \times 30 \mathrm{~min}$ F. C.

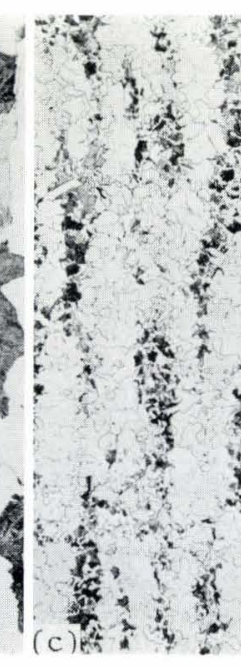

(c) $900^{\circ} \mathrm{C} \times 60 \mathrm{~min}$ F. C.

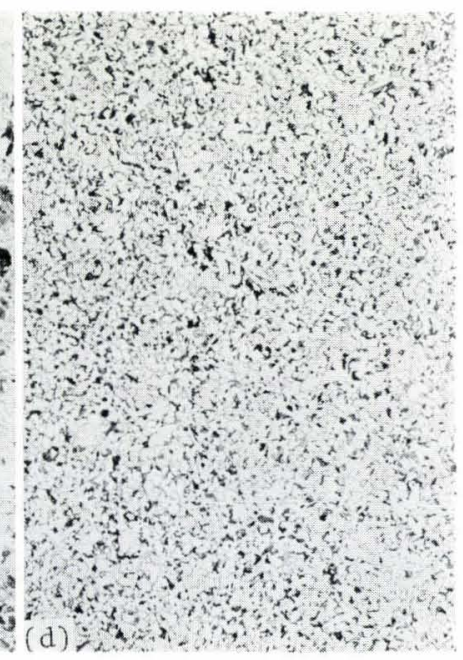

(d) $900^{\circ} \mathrm{C} \times 60 \mathrm{~min} \mathrm{A.} \mathrm{C.}$

Photo. 1. Optical micrographs of the $0.05 \% \mathrm{Si}$ steel $(\times 100)$. 


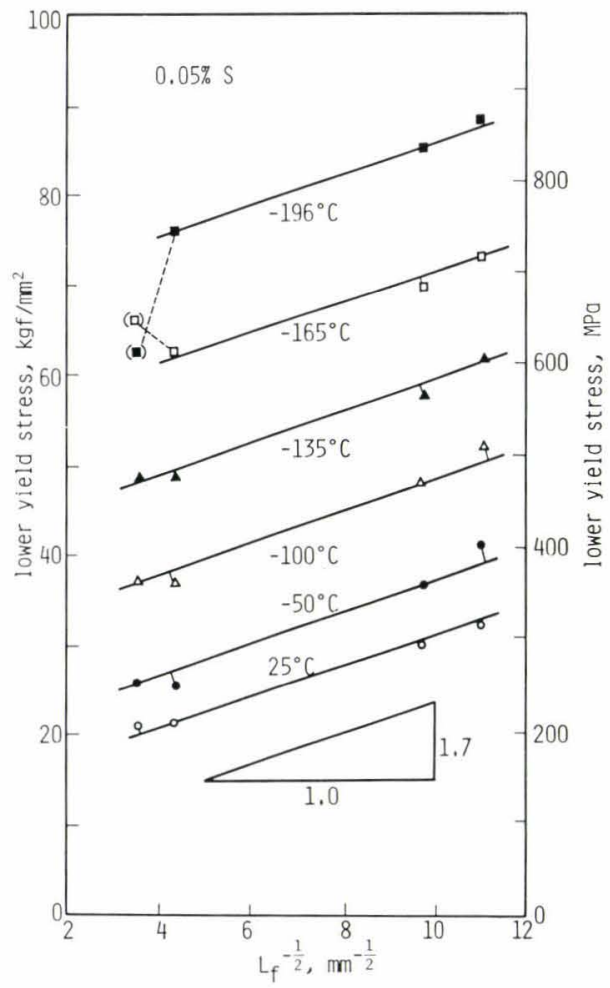

Fig. 5. Relationship between the ferrite grain size and the lower yield stress of the $0.05 \% \mathrm{Si}$ steel.

$1.05 \% \mathrm{Si}$ steel are shown in Figs. 5 and 6 respectively. It has been well established that the lower yield point is linearly related to the inverse root of the mean ferrite grain size $^{7}$ and it is given in Eq (1). The present results are in quite good agreement with this equation:

$$
\sigma_{l y}=\sigma_{0}+k_{y} d^{-1 / 2}
$$

Here, $\sigma_{l y}$ is the lower yield point, $\sigma_{0}$ is the friction stress for the dislocation motion within the ferrite grain, $k_{y}$ is the constant, and $d$ is the mean ferrite grain size. If the ferrite grain size $d$ is expressed as either the linear intercept $L_{f}$ or the grain diameter, the $k_{y}$-value can be obtained as $1.6 \sim 1.7 \mathrm{kgf} / \mathrm{mm}^{2}$ or $2.0 \sim 2.1 \mathrm{kgf} / \mathrm{mm}^{2}$ respectively. These values did not vary with both silicon content and the temperature tested, and are in good agreement with the results published elsewhere. ${ }^{7)}$ The deviations from this relation were observed in the coarse-grained specimens tested at both $-165^{\circ} \mathrm{C}$ and $-196^{\circ} \mathrm{C}$ as in Figs. 5 and 6. These were due to the facts that at $-165^{\circ} \mathrm{C}$ the cleavage fracture initiated at the upper yield point and at $-196^{\circ} \mathrm{C}$ fracture occurred at the stress much lower than the yield stress.

The lower yield points for the steels of which $L_{f}$ is $20.4 \mu \mathrm{m}$, i.e., $L_{f}^{-1 / 2}\left(\mathrm{~mm}^{-1 / 2}\right)$ is 7.0 , were calculated using the relationships such as those shown in Figs. 5 and 6 . The relationship between the lower yield stress for this grain size and the amount of silicon is illustrated in Fig. 7. It can be seen that the solid solution hardening due to $1 \% \mathrm{Si}$ was $6.3 \mathrm{kgf} / \mathrm{mm}^{2}$ at the room temperature but it decreased to $1.8 \mathrm{kgf} / \mathrm{mm}^{2}$ at $-100^{\circ} \mathrm{C}$, and that even the solid solution softening occurred at the temperatures below $-135^{\circ} \mathrm{C}$. This

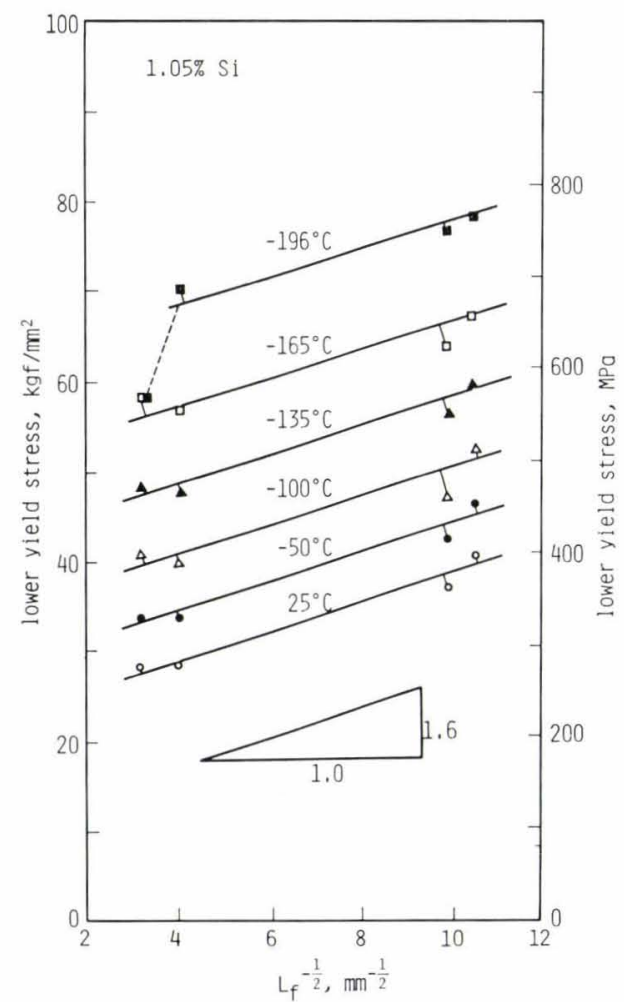

Fig. 6. Relationship between the ferrite grain size and the lower yield stress of the $1.0 \% \mathrm{Si}$ steel.

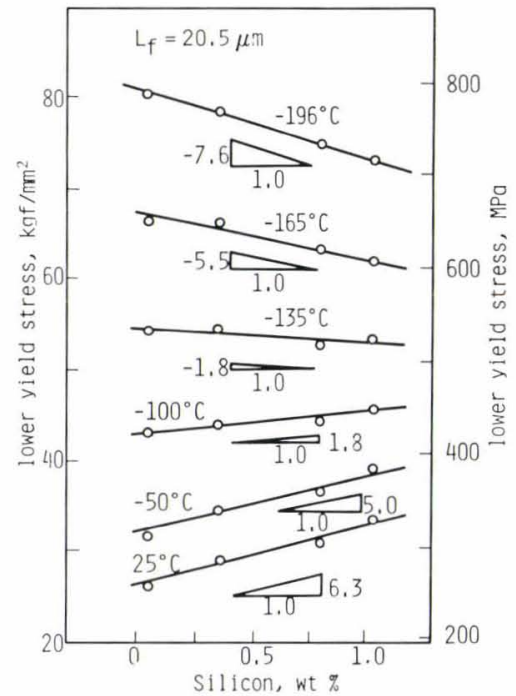

Fig. 7. Effect of the amount of $\mathrm{Si}$ on the lower yield stress at various temperatures at constant ferrite grain diameter, $L_{f}=20.5 \mu \mathrm{m}$.

solid solution softening due to the addition of $1 \% \mathrm{Si}$ reached to $7.6 \mathrm{kgf} / \mathrm{mm}^{2}$ at $-196^{\circ} \mathrm{C}$. The solid solution hardening by $1 \% \mathrm{Si}$ at room temperature obtained in the present study $\left(6.3 \mathrm{kgf} / \mathrm{mm}^{2}\right)$ is slightly smaller than the published data, $7 \sim 10 \mathrm{kgf} / \mathrm{mm}^{2}{ }^{1,2}{ }^{1,2}$

Figure 8 shows the relationship between the 50\% brittle fracture appearance transition temperature in the Charpy test (vTs) and the inverse root of the mean linear intercept of ferrite grains $\left(L_{f}^{-1 / 2}\right)$. This analysis was due to the theory by $\operatorname{Petch}^{8}$ in which the transition temperature is obtained as Eq. (2), and in the limited range of ferrite grain size the transition temperature is approximately linearly related to the 


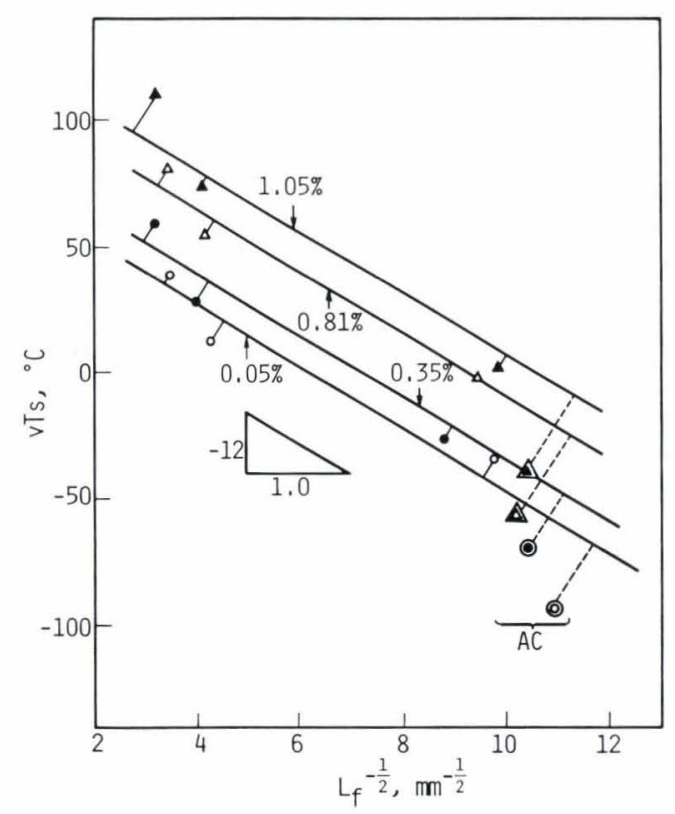

Fig. 8. Relationship between the ferrite grain size and the impact transition temperature. (AC denotes the specimens cooled in air.)

inverse root of ferrite grain size:

$$
T_{c}=K-\beta \ln d^{-1 / 2} \text {. }
$$

where $T_{c}$ is ductile/brittle transition temperature, $K$ and $\beta$ are the constants, and $d$ is the ferrite grain diameter. In the present study, however, the deviations from this relation were observed in the case of a different cooling rate from the austenite as has previously reported for the steels containing nickel and manganese. ${ }^{9)}$ That is, the transition temperatures of the steels cooled in air were $30^{\circ} \sim 40^{\circ} \mathrm{C}$ lower than those expected from the results for the steels furnace-cooled. Thus, the results were analyzed in terms of the mean linear intercepts of pearlite colonies $L_{p}$ assuming that the Griffith's flaw was the pearlite colony crack as in the previous papers. ${ }^{9,10)}$ The results are shown in Fig. 9. It can be seen that the good correlation exists between them and that the pearlite colony crack plays an important roll for the initiation of cleavage crack in ferrite. Comparing the transition temperatures at a given pearlite colony size, the addition of $1 \% \mathrm{Si}$ raises $62^{\circ} \mathrm{C}$ in the transition temperature, the increase of silicon content deteriorating the impact properties as far as the toughness is assessed by Charpy test. This result agrees well with that obtained by Rees et al. ${ }^{11)}$ The vTs, also, exhibited the large microstructural dependence, and the increase of $1 \mathrm{~mm}^{-1 / 2}$ in the inverse root of the mean pearlite colony size $\left(L_{p}^{-1 / 2}\right)$ lowered the vTs about $10^{\circ} \mathrm{C}$.

Figure 10 shows the relationship between the pearlite colony size and the brittle fracture propagation-arrest temperature where the stress intensity factor at the tip of propagating crack was $200 \mathrm{kgf} / \mathrm{mm}^{3 / 2}$ in the DCB test (This temperature will be referred to as $\left.T_{K_{c a=200}}\right)$. The reason to choose $200 \mathrm{kgf} / \mathrm{mm}^{3 / 2}$ for $K_{c}$-value is due to the facts that for the steels used in the present study the plastic zone was rather

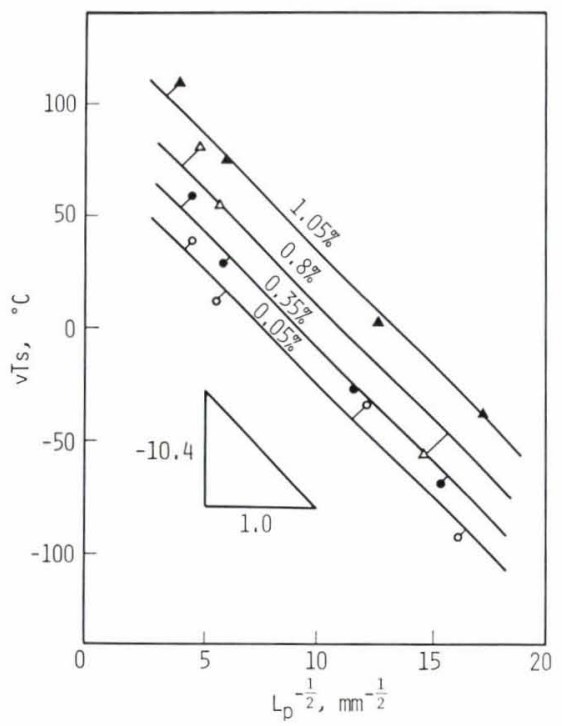

Fig. 9. Relationship between the pearlite colony size and the impact transition temperature. (The percentages shown in the figure are the silicon content.)

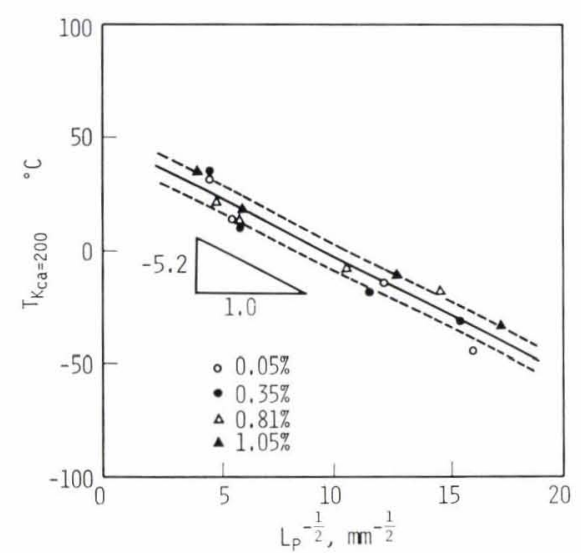

Fig. 10. Relationship between the pearlite colony size and the brittle fracture propagation-arrest temperature.

small and the scattering of the experimental values was small enough to determine the transition temperature. It can be seen that the increase of $1 \mathrm{~mm}^{-1 / 2}$ in $L_{p}^{-1 / 2}$ lowered only $5^{\circ} \mathrm{C}$ in $T_{K_{c a=200}}$ and the microstructural dependency of $T_{K_{c a}}$ was much smaller than that of vTs in Charpy test. It is also interesting to note that the effect of silicon on the propagationarrest properties could not be detected in the DCB test. Figure 11 illustrates the relationship between the amount of silicon and either vTs or $\mathcal{T}_{K_{c a=200}}$ assuming $L_{p}=4.4 \mu \mathrm{m}$, i.e., $L_{p}^{-1 / 2}=15 \mathrm{~mm}^{-1 / 2}$, confirming the conclusion described above.

\section{Discussion}

At a constant ferrite grain size, the lower yield point at room temperature increased linearly with increasing silicon content. With lowering the test temperature, however, the solid solution hardening due to silicon decreased and even the solid solution softening appeared at temperatures below $-135^{\circ} \mathrm{C}$. The solid solution softening at lower temperatures has often been observed in the bcc metals such as 


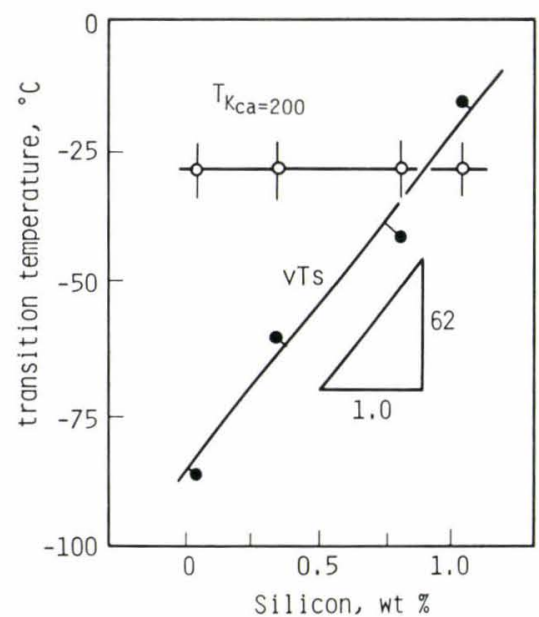

Fig. 11. Effect of the amount of $\mathrm{Si}$ on the brittle fracture characteristics.

Ta-Re alloy, ${ }^{12)} \mathrm{Fe}-3 \% \mathrm{Si}, \mathrm{Fe}-3 \% \mathrm{Mn}$ and $\mathrm{Fe}-3 \% \mathrm{Ni}$ binary alloys. ${ }^{5)}$ This suggests that the temperature dependence of the slip mode in ferrite varied with the addition of solute elements. Since the solid solution softening due to silicon at lower temperatures may correspond to the increase of either the mobility or the multiplication rate of dislocations in the vicinity of the yield point, the low temperature toughness would not always decrease with increasing silicon content.

On the other hand, since the temperature dependence of the plastic deformation can be approximately replaced by the strain rate dependence of it, the plastic properties at lower temperatures will correspond to that at higher temperatures with high strain rate. ${ }^{13)}$ That is, although the Charpy test is dynamic, the strain rate at the tip of mechanical notch at the crack initiation would be rather small because of the large radius of curvature of the notch. Thus the increase of vTs by silicon addition may be due to the solid solution hardening at higher temperatures. The fracture behaviour at higher strain rate such as $T_{K_{c a=200}}$ in the DCB test where the tip of the propagating brittle crack was quite acute, however, is expected to correspond to the deformation mode at lower temperatures. In fact, the effect of silicon in the DCB test could not be detected in accordance with the decrease of the solid solution hardening due to silicon at lower temperatures. There exists, therefore, the possibility to improve the brittle crack-arrest properties at much smaller $K_{c a}$ value with the increase of silicon content, but this was not confirmed in the present study because of the scattering of the experimental data.

Whereas the good correlation has been confirmed between vTs in Charpy test and the temperature exhibiting a given critical crack opening displacement in the static loaded fatigue-notched COD test, such as the temperature at which the critical COD value is $0.2 \mathrm{~mm}\left(T_{\tilde{o}_{c=0,2}}\right)$ as shown in Fig. 12. ${ }^{14)}$ This may be due to the fact that the radius of curvature of the notch in Charpy specimen was much larger than that in the fatigue-notched COD specimen and

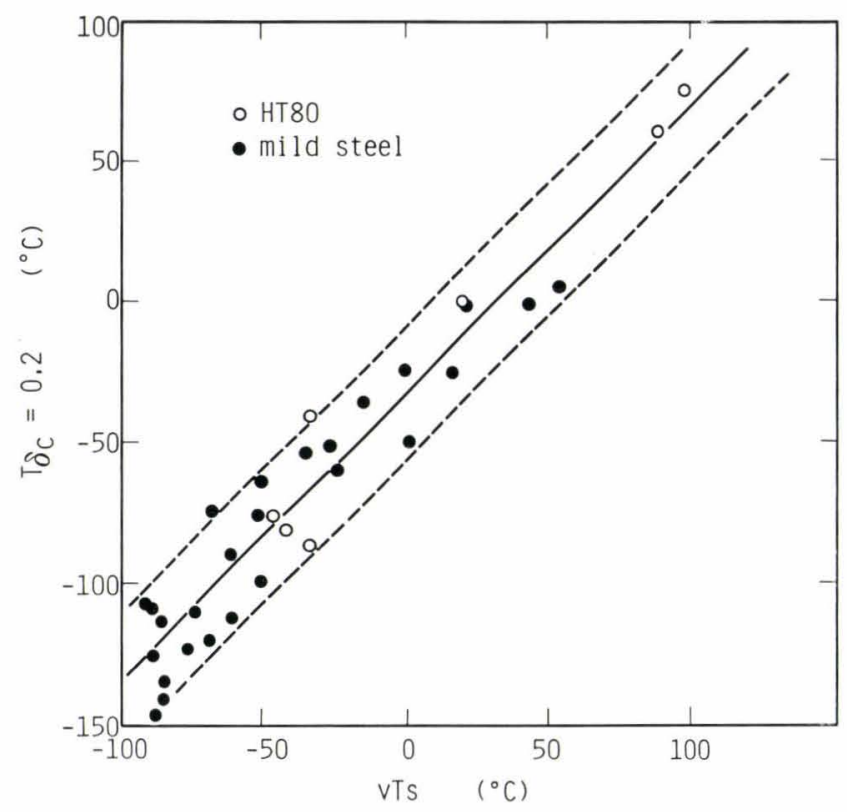

Fig. 12. Relationship between the Charpy impact transition temperature and the brittle fracture initiation temperature by the COD specimen with fatigue notch.

that the strain rate at the notch in Charpy test may be in the same order with that in the static loaded COD test. In fact, it has been confirmed previously ${ }^{9}$ ) that $T_{\tilde{o}_{c}=0.4}$ and $T_{\tilde{o}_{c}=0,04}$ in the static loaded COD tests exhibited large microstructural dependence and lowered $11^{\circ}$ and $8^{\circ} \mathrm{C}$ respectively with the increase of $1.0 \mathrm{~mm}^{-1 / 2}$ in $L p^{-1 / 2}$. These results are in quite good agreement with the present study where vTs decreased $10^{\circ} \mathrm{C}$ with the increase of $1.0 \mathrm{~mm}^{-1 / 2}$ in $L_{p}^{-1 / 2}$. Considering the results described above, the brittle fracture initiation properties from the fatigue notch in the static loaded COD test is expected to deteriorate with the increase of silicon content as in the case of vTs.

\section{Conclusions}

The effect of silicon on the strength and the toughness of ferritic-pearlitic steels have been investigated and the following results were obtained:

(1) The increase of silicon content from $0.05 \%$ to $1.05 \%$ did not affect either ferrite grain or pearlite colony sizes, and the coarseness of the microstructure was dominated by heat treatment.

(2) Comparing the strength at a constant ferrite grain size, the large solution hardening due to silicon was observed at room temperature, but it decreased with lowering temperature, the solid solution softening being recognized at temperatures below $-135^{\circ} \mathrm{C}$.

(3) The $50 \%$ brittle fracture transition temperature $(\mathrm{v} T \mathrm{~s})$ in the Charpy impact test depended largely on the microstructure and the increase of $1 \mathrm{~mm}^{-1 / 2}$ in the inverse root of mean pearlite colony size $\left(L_{p}^{-1 / 2}\right)$ lowered $10^{\circ} \mathrm{C}$ in vTs. At the same pearlite colony size, the increase of $0.1 \% \mathrm{Si}$ raised $6^{\circ} \mathrm{C}$ in vTs.

(4) Since the vTs is in good correlation with the brittle fracture initiation temperature which exhibits a given critical COD value in the fatigue notched 
static specimen, it can be thought that the brittle fracture initiation properties exhibit a large microstructural dependence and deteriorate with the increase of silicon content.

(5) The brittle fracture propagation-arrest characteristics determined by the DCB test was not largely affected by both the microstructure and the silicon content.

\section{Acknowledgements}

Sincere thanks are due to Dr. N. Oda, the General Manager of Sumitomo Metal Industries, Ltd., Dr. K. Nishioka and Dr. T. Shiraiwa, the Assistant Managers of the Central Research Laboratories for their permission to publish this paper.

Thanks are also due to Dr. Y. Ito for his encouragement during the course of this research.

\section{REFERENCES}

1) R. H. Frazier, F. W. Boulger and C. H. Lorig: Trans. Met. Soc. AIME, 210 (1956), 1269.
2) T. Gladman, I. D. Mcivor and F. B. Pickering: JISI, 210 (1972), 916.

3) C. E. Lacy and M. Gensamer: Trans. ASM, 32 (1944), 88.

4) S. Takeuchi: J. Phys. Soc. Japan, 27 (1969), 929.

5) W. C. Leslie: Met. Trans. 3 (1972), 5.

6) S. Hasebe and Y. Kawaguchi: Tetsu-to-Hagané, 61 (1975), 875.

7) N. J. Petch: JISI, 174 (1953), 25.

8) N. J. Petch: Fracture (Proc. Swampscott Conf.), John Wiley \& Sons Inc., New York, (1959), 54.

9) Y. Ohmori, H. Iwanaga, Y. Kawaguchi and F. Terasaki: Trans. ISIJ, 16 (1976), 388.

10) Y. Ohmori and F. Terasaki: Trans. ISIJ, 16 (1976), 561.

11) W. P. Rees, B. E. Hopkins and H. R. Tipler: JISI, 177 (1954), 93.

12) T. E. Mitchell and P. L. Raffo: Canad. J. Phys., 45 (1967), 1047.

13) T. R. Wilshaw and P. L. Pratt: Proc. First Int. Conf. on Fracture, Jap. Soc. for Strength \& Fracture of Materials, Sendai, 2 (1965), 973.

14) H. Iwanaga and Y. Ohmori: Unpublished data. 